\title{
REVIEW
}

\section{Striving to cure adult T-cell leukaemia/lymphoma: a role for allogeneic stem cell transplant?}

\author{
EH Phillips ${ }^{1}$, A Hodson $^{2}$, O Hermine ${ }^{3}$, A Bazarbachi $^{4}$ and K Cwynarski ${ }^{1}$
}

\begin{abstract}
Adult T-cell leukaemia/lymphoma (ATL) is an aggressive HTLV-1-related malignancy, rare outside of regions where the retrovirus is endemic. Although the use of antiviral therapy has improved outcomes, particularly for indolent forms of ATL, response to combination chemotherapy is poor and outcomes for aggressive subtypes remains dismal. Consolidation with allogeneic stem cell transplant (alloSCT) has an increasing role in the management of ATL in eligible patients, offering favourable long-term remission rates. However, relatively high-transplant-related mortality and issues with donor recruitment for certain ethnicities remain problematic. In this review, we discuss the rationale for and issues surrounding alloSCT in ATL in the context of conventional and emerging therapies.
\end{abstract}

Bone Marrow Transplantation (2016) 51, 1549-1555; doi:10.1038/bmt.2016.154; published online 12 September 2016

\section{INTRODUCTION}

Adult T-cell leukaemia/lymphoma (ATL) is a rare but aggressive peripheral T-cell lymphoma causally linked to infection with the retrovirus human T-lymphotropic virus-1 (HTLV-1). ${ }^{1}$ ATL is usually diagnosed in individuals from areas of HTLV-1 endemicity including Japan, the Caribbean, South America, West Africa, Melanesia and the Middle East. Between 3 and 5\% of HTLV-1infected individuals develop ATL with onset most frequent in the 5th-6th decade., ${ }^{2,3}$ In Western countries peripheral T-cell lymphoma accounts for $5-10 \%$ of all non-Hodgkin's lymphoma, with ATL comprising just $1-2 \%$ of cases, whereas in Asia peripheral T-cell lymphoma comprises $15-20 \%$ of non-Hodgkin's lymphoma cases, of which $\sim 25 \%$ are ATL, particularly in Japan., ${ }^{4,5}$

ATL is classified according to the Shimoyama classification, ${ }^{6}$ comprising four subtypes with widely differing 4-year survival rates: smouldering (52\%), chronic (36\%), lymphomatous (16\%) and acute $(11 \%)^{7}$ Other major prognostic factors include advanced performance status, high lactate dehydrogenase, age $\geqslant 40$ years and hypercalcaemia. ${ }^{8}$ Molecular aberrations associated with poor prognosis include mutation or deletion of the tumour suppressor genes $\mathrm{p} 53^{9,10}$ and $\mathrm{p} 15 / 16^{10,11}$

Lymphoma is the most frequent indication for haemopoietic stem cell transplantation in Europe. ${ }^{12}$ While the majority are autologous haemopoietic stem cell transplants (autoSCT), use of allogeneic haemopoietic stem cell transplantation (alloSCT) has increased, particularly since the advent of reduced intensity (RI) conditioning protocols. In aggressive forms of ATL, there is increasing evidence for alloSCT but the relatively hightransplant-related mortality (TRM) remains problematic. Given the rarity of ATL, there are very few randomised, prospective trials to guide management. Most of the evidence in favour of alloSCT is based on data from large Japanese transplant registry studies, whilst experience outside of endemic areas is relatively limited. This review focuses on published data regarding the role primarily of alloSCT in ATL and outlines its use in the context of currently available treatment modalities.

\section{FIRST-LINE TREATMENT: CHEMOTHERAPY AND ANTIVIRAL THERAPY}

Complex dose intense combination chemotherapy improves response rates and PFS, but so far a significant impact on overall survival (OS) has not been demonstrated with any individual regimen. ${ }^{13,14}$ Factors that potentially account for this include intrinsic drug resistance secondary to p53 dysfunction ${ }^{15}$ or overexpression of multi-drug resistance proteins, ${ }^{16,17}$ an older patient population with comorbidities, and frequent opportunistic infections due to acquired cellular immunodeficiency associated with HTLV-I infection. Response rates above $70 \%$ have been reported with the intensive multi-drug regimen $\mathrm{mLSG} 15,{ }^{13,14,18}$ which were superior to CHOP-14 in a randomised phase 3 study. ${ }^{13}$ However, a trend towards improved OS did not reach statistical significance ( 24 vs $13 \%$, respectively, two-sided $P=0.169$ ). ${ }^{13}$ ATL lymphoma patients seem to benefit more from this dose intense regimen, whereas for acute ATL, CR rates with LSG15 are below $20 \%$ and 4 -year OS is $<15 \% .{ }^{14}$ Intrathecal chemotherapy is recommended with acute/lymphoma subtypes to prevent frequent meningeal relapse. ${ }^{19}$

The efficacy of antiviral therapy (AVT) with zidovudine and interferon-alpha (IFN- $\alpha$ ) has been demonstrated in multiple studies. $^{20-24}$ It is particularly effective in chronic and smouldering ATL, with $100 \% 5$-year survival in an international meta-analysis $(n=17){ }^{20}$ In acute ATL, both first-line and maintenance AVT significantly improved OS over chemotherapy alone. Outcomes, however, remained poor with a median OS of 6 months and 5 -year OS of $15 \%$ for the whole cohort and $28 \%$ for patients treated with AVT alone. In lymphomatous ATL, first-line treatment with AVT alone resulted in a significant survival disadvantage compared with chemotherapy; ${ }^{20}$ best results were obtained with chemotherapy combined with AVT. ${ }^{24}$

The efficacy of novel agents including arsenic trioxide, ${ }^{25,26}$ Lenalidomide, $^{27}$ Bortezomib ${ }^{28-30}$ and monoclonal antibodies against CCR4 (Mogamulizumab), ${ }^{18,31}$ CD25 (Daclizumab), ${ }^{32,33}$ CD52 (Alemtuzumab) ${ }^{34,35}$ and CD30 are being explored but these

\footnotetext{
${ }^{1}$ Department of Haematology, University College Hospital, London, UK; ${ }^{2}$ Department of Haematology, Ipswich Hospital, Ipswich, UK; ${ }^{3}$ Department of Hematology, Imagine Institute, Assistance Publique Hôpitaux de Paris, Paris Descartes University, Necker Hospital, Paris, France and ${ }^{4}$ Department of Internal Medicine, American University of Beirut, Medical Center, Beirut, Lebanon. Correspondence: Dr K Cwynarski, Department of Haematology, University College Hospital, 3rd Floor West, 250 Euston Road, London NW1 2PG, UK. 
treatments remain experimental for the most part. The combination of arsenic trioxide and AVT is effective and induces rapid and prolonged responses in chronic ATL. ${ }^{25,36}$ Promising results are reported in lymphoma/acute ATL with combined arsenic trioxide/IFN-a consolidation following chemotherapy or AVT to eradicate minimal residual disease (reference 37 and O. Hermine, unpublished data). Single agent Mogamulizumab has shown promise with an overall response rate of $50 \%$ and median OS of 13.7 months in relapsed aggressive ATL. ${ }^{31}$ The potential of immunochemotherapy was explored in a randomised phase 2 trial; the addition of Mogamulizumab to combination chemotherapy improved response rates, albeit with increased toxicity and survival data are immature. ${ }^{18}$

The prognosis of aggressive ATL subtypes remains dismal with a median survival of $<12$ months. ${ }^{7,20}$ Some groups have attempted to define cohorts of patients that may fare well with current therapies. For a proportion of acute ATL patients achieving CR with AVT alone $(29.7 \%)$, 5-year OS was $82 \%{ }^{20}$ Kawada et al. ${ }^{38}$ reported a 3-year OS of $61.5 \%$ with chemotherapy alone for 15 patients with serum soluble IL-2 receptor (s-IL2R) levels $<2000 \mathrm{iU} / \mathrm{mL}$ for over 3 months. However, it is clear that current treatment regimens are suboptimal for the majority of patients with aggressive ATL, and therefore many groups have adopted transplant strategies as consolidation to improve survival rates in eligible patients.

\section{AUTOLOGOUS HAEMATOPOIETIC STEM CELL TRANSPLANTATION}

Published data on autoSCT is limited to retrospective case reports or series. Owing to the variety of chemotherapy regimens used for induction, conditioning and, in some cases, post autoSCT consolidation, it is difficult to derive meaningful data but outcomes have generally been poor. The largest Japanese series to date reports eight cases of autoSCT for ATL, all of whom relapsed or died of transplant complications, with a median remission of only 3.5 months. ${ }^{39}$ In an American case series, all four relapsed ATL patients progressed within 18 months of autoSCT. ${ }^{40}$ An additional four cases of autoSCT were recently reported by the European Society for Blood and Marrow Transplantation (EBMT) Registry, all of whom died within 1 year. ${ }^{41}$ No published data on the use of AVT in conjunction with autoSCT exist. Two case reports suggest efficacy may be improved if IFN-a therapy is commenced following autoSCT. ${ }^{42,43}$ Ongoing remission at 26 months with IFN-a maintenance represents the longest reported remission post autoSCT. ${ }^{42}$ Given the rarity of sustained remissions, there is no discernible benefit of autoSCT consolidation.

\section{ALLOGENEIC HAEMATOPOIETIC STEM CELL TRANSPLANTATION}

AlloSCT offers a range of potential benefits over autoSCT. First, there is no potential for graft contamination by ATL. Second, there is the potential for development of a graft-vs-ATL (GvL) response to control or eliminate residual disease. Third, long-term remissions have been reported in approximately a third of alloSCT recipients, ${ }^{44-46}$ which, in a proportion, is likely to be synonymous with cure. This is offset, however, against an increased TRM, requiring careful donor and patient selection, taking into consideration age and co-morbidities.

There has been no randomised comparison of chemotherapy alone vs alloSCT consolidation. A single centre retrospective study showed improved 3-year OS in alloSCT recipients $(n=29)$ over those receiving chemotherapy alone $(n=37 ; 44.9$ vs $27.7 \%$ $P<0.05){ }^{38}$ Baseline characteristics of alloSCT and non-SCT groups appear similar but selection bias is an inherent issue. ${ }^{38}$ The largest retrospective analysis of alloSCT in Japan included outcome data on 578 patients with ATL transplanted between February 1992 and December $2009 .{ }^{47}$ Three-year OS was $36 \%$ with a median OS of 9-10 months and TRM of 34\%.

Most reports are derived from retrospective analyses of Japanese Registry Data. This represents a population less genetically diverse than other countries where ATL is prevalent. GvHD rates may be lower in Japanese compared with Western populations through reduced HLA diversity. ${ }^{48}$ Thus direct translation of these results to other ethnic groups must be with caution. The EBMT registry recently reported 3-year OS rates of $34.3 \%$ in a cohort of 17 ATL patients, ${ }^{41}$ demonstrating that alloSCT is a feasible strategy outside of Japan.

\section{RECIPIENT FACTORS}

Male sex, increased age ( $>50$ years) and reduced performance status have been consistently associated with inferior outcomes. ${ }^{44,47,49}$ Better outcomes are achieved when transplanted in first clinical remission ${ }^{7}$ and, for related donors, when transplanted early in the disease course ( $<100$ days after diagnosis). ${ }^{50}$ Failure to achieve CR before alloSCT also correlates with worse outcomes, although long-term remission can still be achieved in a small proportion of patients. A Japanese registry study $(n=386)$ reported a survival probability of $26 \%$ in patients failing to achieve CR vs $51 \%$ for those transplanted in first $\mathrm{CR}^{44}$ Several small retrospective studies suggest high sIL-2R levels prior to transplant predict adverse OS on univariate analysis, ${ }^{38,51}$ presumably as a surrogate marker for ATL burden. No clear impact of ATL subtype on outcome following alloSCT has been demonstrated. ${ }^{49}$

\section{DONOR SELECTION}

Given the rapidly progressive nature of $A T L$, consideration of alloSCT should commence early in disease management to minimise delay. Table 1 outlines results from the largest prospective and retrospective trials according to donor source.

Sibling donors are preferred due to donor accessibility and superior outcomes, although in Japan only one in three ATL patients have a matched sibling donor, of whom two-thirds are HTLV- 1 carriers. ${ }^{54}$ A retrospective study of 113 patients achieving CR post-alloSCT suggests higher disease-related mortality with HTLV-1-positive donors on multivariate analysis, but ultimately no difference in OS. ${ }^{44}$ There are two reports of donor-derived ATL arising 4 months ${ }^{55}$ and 9 years ${ }^{56}$ post alloSCT from HTLV-1-positive siblings. Thus, HTLV-1 seronegative donors are often preferred, although there is little evidence to support this at present.

In Japan, a suitable unrelated donor will be found in one-third of cases. In Europe and America, where most patients with ATL are of African or African-American descent, donors of similar ethnic origin continue to be under-represented in donor registries. In the UK, African/Afro-Caribbean donors accounted for only $2.4 \%$ of donors of known ethnic origin. ${ }^{57}$

Early reports of unrelated donor alloSCT were unfavourable. None of the 15 recipients in an early study survived $>500$ days. ${ }^{58}$ Since then, multiple studies have demonstrated the efficacy of using unrelated donors in ATL. ${ }^{44,59,60}$ A recent analysis demonstrated significantly inferior OS with unrelated donors $(n=306)$ compared with HLA-matched siblings $(n=210)$, although the frequency of HLA mismatch in the unrelated group was not stated. ${ }^{47}$ Reports on alloSCT with partially matched related donors suggest feasibility, although outcome may be inferior (Table 1). ${ }^{44,47}$

Very few data exist on the use of haploidentical donors in ATL specifically. In one study, three patients with refractory ATL received haploidentical sibling alloSCT matched for non-inherited maternal antigens. One patient died of GvHD while the others relapsed. ${ }^{61}$ Although small numbers of haploidentical transplants have been included in larger series, ${ }^{41,44}$ outcomes for these 
Table 1. Outcomes of prospective and major retrospective trials in alloSCT for aggressive ATL, focussing on donor source and pre-transplant conditioning

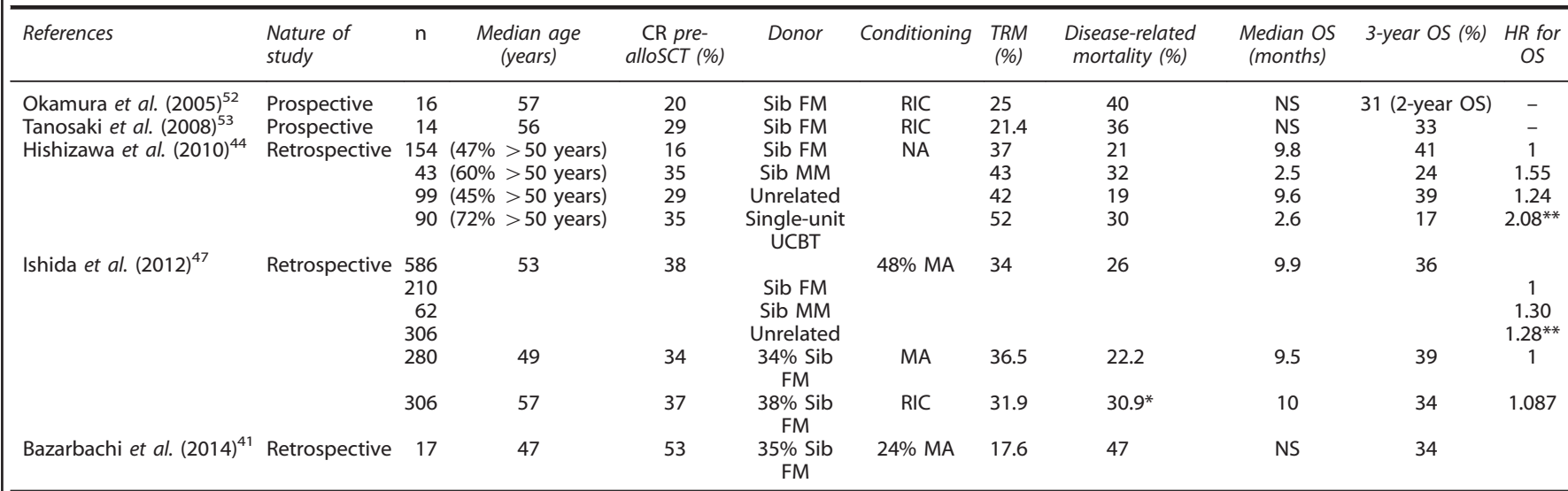

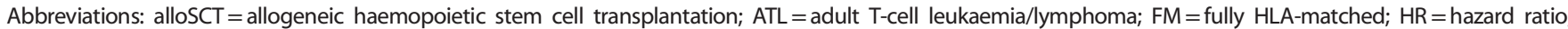
$\mathrm{MA}=$ myeloablative; $\mathrm{MM}=$ partial $\mathrm{HLA}$ mismatch; $\mathrm{NA}=$ not available; $\mathrm{OS}=$ overall survival; $\mathrm{RIC}=$ reduced intensity conditioning; Sib = sibling; TRM = transplant related mortality; UCBT $=$ umbilical cord blood transplantation. ${ }^{*} P<0.05$ compared with MA conditioning. ${ }^{* *} P<0.05$ compared with FM sib alloSCT.

patients have not been individually reported. Major concerns include higher $\mathrm{TRM}^{62}$ although recent data suggest reasonable outcomes with newer protocols for haploidentical alloSCT in other haematological malignancies, including older patient cohorts. ${ }^{63,64}$ This approach remains experimental in ATL.

\section{UMBILICAL CORD BLOOD TRANSPLANTATION (UCBT)}

Durable remissions have been achieved with single and double-unit UCBT. ${ }^{44,65,66}$ A major benefit is the rapid access to donor units. Rates of GvHD are lower than with unrelated donors, allowing use of partially HLA-mismatched units; although this may potentially compromise a GvL effect. Furthermore, donor lymphocyte infusion is not an option for relapse post-alloSCT.

A retrospective analysis of single-unit UCBT in ATL $(n=90)$ demonstrated inferior outcomes with high rates of graft failure (17\%, median CD34+ cell dose $2.55 \times 10^{7}$ ) and high TRM $(51 \%)$, although ATL-related mortality was similar to other donor sources. Median OS was just 2.6 months with 3 -year OS of $17 \% .{ }^{44}$ Patient selection and disease status at SCT are crucial; a retrospective analysis of 27 ATL patients receiving UCBT reported 3-year OS of $50 \%$ for 16 patients achieving at least partial response pre-alloSCT, but only $9.1 \%$ for those with chemorefractory disease. ${ }^{67}$ Little is known about the comparative efficacy of double-unit UCBT in ATL, which might reduce the high TRM by reducing graft failure rates and hastening count recovery. Given that UCBT in other mature lymphoid neoplasms can achieve outcomes similar to unrelated donor alloSCT, ${ }^{68}$ its role warrants further exploration but optimisation of UCBT protocols is required before routine use in ATL.

\section{CONDITIONING REGIMENS}

Given that HTLV-1-related ATL has a long latency with a median presentation of over 60 years of age, RI regimens are increasingly used. Myeloablative (MA) alloSCT regimens, although feasible in younger recipients, are now less commonly performed. $\mathrm{RI}$ conditioning regimens have less cytotoxic potential, therefore alloSCT is more reliant on GvL effect. The feasibility of RI regimens in older patients (50-67 years) was demonstrated in two prospective trials. ${ }^{52,53}$ Importantly, a large Japanese retrospective study of 586 alloSCT recipients demonstrated no difference in OS between $\mathrm{MA}$ and $\mathrm{RI}$ conditioning on multivariate analysis, ${ }^{47}$ although suggestive of a trend towards improved OS with RI conditioning in patients aged $56-72$ years $(P=0.072$; Table 1$)$. Although TRM was marginally higher in MA alloSCT patients, this did not reach statistical significance; whereas ATL-related mortality was significantly higher in RI over MA alloSCT (hazard ratio $1.579 P=0.019){ }^{47}$

No prospective comparison of conditioning regimens has been undertaken. Japanese data suggest that fludarabine-based conditioning regimens in combination with melphalan for $\mathrm{RI}$ alloSCT are superior to those incorporating busulphan (hazard ratio for OS $0.645, P=0.015)$. For MA alloSCT, TBI, melphalan and busulphan-based regimens have all been used, with no clear difference in outcomes. ${ }^{47}$

The role of in vivo T-cell depletion with ATG or alemtuzumab has not been fully explored; most Japanese patients receive T-replete transplants. ${ }^{44}$ Alemtuzumab has shown some efficacy in ATL outside of the transplant setting, ${ }^{34,35}$ but could also risk suppressing an early GvL effect in a rapidly relapsing malignancy. A high rate of early relapse was noted in a phase 1 study incorporating low dose ATG $(5 \mathrm{mg} / \mathrm{kg}$ ) with fludarabine/busulphan conditioning. $^{52}$ However, a follow-on study omitting ATG demonstrated similar survival rates without an increase in GvHD, although numbers were small. ${ }^{53}$

The G-CSF receptor is expressed on ATL cells, with evidence of G-CSF-induced ATL proliferation in a small proportion of patients, leading to theoretical concern that G-CSF administration may promote disease progression. ${ }^{69,70}$ Whether this correlates with clinical outcomes, however, is unclear.

\section{INFECTIVE COMPLICATIONS}

TRM and infectious complications are relatively high in ATL patients, partly attributable to HTLV-1-mediated immunodeficiency. A recent study reported 1-year infection-related mortality of $14.7 \%$ in ATL patients post alloSCT $(n=68)$, which was higher than in acute myeloid and acute lymphoblastic leukaemia patients $(6.1 \%$ and $2.0 \%$, respectively) on univariate analysis only, and attributable to a range of bacterial, viral and fungal pathogens. ${ }^{71}$ CMV infection, assessed by pp65 antigen detection, was associated with inferior OS on multivariate analysis in ATL only. ${ }^{71}$ 


\section{IMMUNE RECONSTITUTION: GVH VS GVL EFFECT}

The association of GvHD with rates of long-term remission implies the presence of a GvL effect. ${ }^{46,59}$ A retrospective study of alloSCT in 616 Japanese ATL patients showed improved OS in patients with both limited acute GvHD (grades I-II) and extensive chronic GvHD compared with patients without GvHD. There was also a trend towards improved OS in those limited stage chronic GvHD. Severe acute GvHD (grades III-IV) was associated with inferior OS. $^{49}$

The observation that some ATL relapses can be successfully managed with a withdrawal of immunosuppression supports the presence of a GvL effect. $52,53,72,73$ In a recent retrospective study, 2 out of 29 patients with relapsed ATL post alloSCT achieved $C R$ with withdrawal of immunosuppression alone, both in association with emergence of GvHD. ${ }^{74}$ Long-term remissions have been reported with donor lymphocyte infusion, in all cases associated with exacerbation of GvHD. ${ }^{7,75}$ Five of nine patients responded clinically to donor lymphocyte infusion, three of whom achieved a durable CR ( $>3$ years). ${ }^{74}$ Conventional chemotherapy alone was ineffective in all cases of systemic relapse in this study. ${ }^{74}$

Vigorous HTLV-1-specific cytotoxic $T$ lymphocyte (CTL) responses have been demonstrated in ATL patients following alloSCT, which were not detectable pre-transplant. ${ }^{76,77}$ These CTLs are cytotoxic to ATL cells in in vitro and animal studies. ${ }^{78,79}$ Multiple HTLV-1-related epitopes have been identified as targets including the retroviral Tax protein, ${ }^{76,78,80}$ and basic leucine zipper factor. ${ }^{77,81}$ One study identified Tax-specific T-cell responses in $68.8 \%$ of alloSCT recipients $(n=16)$, all of whom had $100 \%$ donor chimerism. ${ }^{82}$ HTLV-1-specific CTLs can persist in long-term survivors $^{83}$ and a small study $(n<5)$ has suggested this may correlate with ongoing ATL remission. ${ }^{76}$ Recently, Tax-specific CD4+ $T$ cells were identified in ATL patients post alloSCT, which were shown to augment CD8+ CTL expansion and are likely to contribute to a GvL effect. ${ }^{82}$

HTLV-1-specific proteins are attractive and specific targets for potential immunotherapy. Modified T-cells expressing receptors targeting HTLV-1-specific epitopes have been developed against both human telomerase reverse transcriptase ${ }^{84}$ and $\operatorname{Tax}^{79}$ with some evidence of ATL response in preclinical studies. ${ }^{79,84}$ Recombinant vaccinia virus-based vaccines expressing basic leucine zipper peptides have also shown preclinical efficacy. ${ }^{81}$

In addition to direct anti-ATL effects, Mogamulizumab suppresses regulatory T-cell function, theoretically enhancing a $\mathrm{GvL}$ response in post-alloSCT relapse, although its efficacy in this setting is confined to a single case report. ${ }^{85}$ However, there is also concern that mogamulizumab, particularly when administered pre-transplant, may increase acute $\mathrm{GvH}$ and non-relapse mortality. ${ }^{86,87}$ Enhancing the GvL response whilst minimising $\mathrm{GvH}$ is problematic, as with all haematological malignancies, but at present there is no evidence to suggest use of specific $\mathrm{GvH}$ prophylaxis strategies, or pre-emptive donor lymphocyte infusion, in ATL patients.

\section{HTLV-1, MINIMAL RESIDUAL DISEASE AND MAINTENANCE THERAPY}

Development of non-malignant HTLV-1-mediated disease is a potential concern following post-alloSCT immunosuppression but is confined to a single case report of HTLV- 1 encephalitis ${ }^{88}$ and a postulated case of HTLV-1-associated myelopathy. ${ }^{89}$ There are multiple reports of acute HTLV-1 complications following solid organ transplantation from HTLV-1-positive donors. ${ }^{90}$ In a recent study, reporting the kinetics of early HTLV-1 infection in three recipients of solid organ transplants from HTLV-1-positive donors, infection disseminated rapidly despite early AVT, peaking at
6 weeks post transplant with early clonal expansion. The extent to which pre-existing anti-HTLV-1 immune responses mitigate this in ATL patients has not been fully explored.

The ability of alloSCT to eradicate HTLV-1 is well documented. ${ }^{46,91-93}$ HTLV-1 eradication, however, is not essential; a proportion of long-term survivors maintain stable proviral loads at pre-alloSCT levels. ${ }^{46}$ Recurrence of HTLV-1 may herald disease relapse, ${ }^{72}$ but may also represent de novo infection of donor lymphocytes, where patients in ongoing remission have shown reemergence of HTLV-1 despite maintaining full donor chimerism. ${ }^{46,53,72,94}$ Analysis of HTLV-1 provirus insertion sites can assess HTLV-1 clonality ${ }^{95,96}$ and might allow detection of emergent clones with the same insertion site as the original ATL clone as an minimal residual disease marker, although its use in this context is not validated. In theory, using AVT following alloSCT may prevent infection of donor T-cells in an immune-compromised environment; we have observed a reduction in proviral loads after AVT in one patient (O Hermine, unpublished data). However, there are very few data to validate the use of AVT, or any other maintenance therapy, in the postalloSCT setting to date. The role of HTLV-1 monitoring and AVT post-alloSCT warrants further investigation but is uncertain at present.

\section{CONCLUSION}

AlloSCT consolidation has a pivotal role in managing aggressive ATL. However, it is important to note that outcomes, in general, have only marginally improved over recent decades with a minority $(<20 \%)$ of acute/lymphoma ATL patients receiving alloSCT, ${ }^{7,24}$ presumably due to donor availability, patient comorbidities/age or disease behaviour. To widen access, improved donor recruitment from relevant ethnic groups and research into optimising outcomes with mismatched or UCB donors is needed. Outcomes for treatment-refractory patients remain extremely poor, regardless of treatment strategy, and research into novel agents and immunotherapy is crucial. Currently alloSCT is the preferred option where feasible but more information on prognostic factors and outcomes, with and without alloSCT consolidation, will help to select those who will derive the most benefit from alloSCT in future.

\section{CONFLICT OF INTEREST}

The authors declare no conflict of interest.

\section{REFERENCES}

1 Yoshida M, Miyoshi I, Hinuma Y. Isolation and characterization of retrovirus from cell lines of human adult T-cell leukemia and its implication in the disease. Proc Natl Acad Sci USA 1982; 79: 2031-2035.

2 Hanchard B. Adult T-cell leukemia/lymphoma in Jamaica: 1986-1995. J Acquir Immune Defic Syndr Hum Retrovirol 1996; 13: S20-S25.

3 Tajima K. The 4th nation-wide study of adult T-cell leukemia/lymphoma (ATL) in Japan: estimates of risk of ATL and its geographical and clinical features. The T- and B-cell Malignancy Study Group. Int J Cancer 1990; 45: 237-243.

4 Anderson JR, Armitage JO, Weisenburger DD. Epidemiology of the non-Hodgkin's lymphomas: distributions of the major subtypes differ by geographic locations. Ann Oncol 1998; 9: 717-720.

5 Vose JM, Neumann M, Harris ME. International peripheral T-cell and natural killer/T-cell lymphoma study: pathology findings and clinical outcomes international T-cell lymphoma project. J Clin Oncol 2008; 26: 4124-4130.

6 Shimoyama M. Diagnostic criteria and classification of clinical subtypes of adult T-cell leukaemia-lymphoma. A report from the Lymphoma Study Group (1984-87). Br J Haematol 1991; 79: 428-437.

7 Katsuya H, Ishitsuka K, Utsunomiya A, Hanada S, Eto T, Moriuchi $\mathrm{Y}$ et al. Treatment and survival among 1594 patients with ATL diagnosed in the 2000s: a report from the ATL-PI project performed in Japan. Blood 2015; 126: 2570-2577.

8 Shimoyama M, Takatsuki K, Araki K, Ichimaru M, Hanada S, Matsumoto M et al. Major prognostic factors of patients with adult T-cell leukemia-lymphoma: a 
cooperative study. Lymphoma Study Group (1984-1987). Leuk Res 1991; 15: 81-90.

9 Sakashita A, Hattori T, Miller CW, Suzushima H, Asou N, Takatsuki K et al. Mutations of the p53 gene in adult T-cell leukemia. Blood 1992; 79: 477-480.

10 Tawara M, Hogerzeil SJ, Yamada Y, Takasaki Y, Soda H, Hasegawa H et al. Impact of p53 aberration on the progression of Adult T-cell Leukemia/Lymphoma. Cancer Lett 2006; 234: 249-255.

11 Yamada Y, Hatta Y, Murata K, Sugawara K, Ikeda S, Mine M et al. Deletions of p15 and/or p16 genes as a poor-prognosis factor in adult T-cell leukemia. J Clin Oncol 1997; 15: 1778-1785.

12 Baldomero H, Gratwohl M, Gratwohl A, Tichelli A, Niederwieser D, Madrigal A et al. The EBMT activity survey 2009: trends over the past 5 years. Bone Marrow Transplant 2011; 46: 485-501.

13 Tsukasaki K, Utsunomiya A, Fukuda H, Shibata T, Fukushima T, Takatsuka $Y$ et al. VCAP-AMP-VECP compared with biweekly CHOP for adult T-cell leukemialymphoma: Japan Clinical Oncology Group study JCOG9801. J Clin Oncol 2007; 25: 5458-5464.

14 Yamada $Y$, Tomonaga M, Fukuda $H$, Hanada S, Utsunomiya A, Tara $M$ et al. A new G-CSF-supported combination chemotherapy, LSG15, for adult T-cell leukaemia-lymphoma: Japan Clinical Oncology Group Study 9303. Br J Haematol 2001; 113: 375-382.

15 Datta A, Bellon M, Sinha-Datta U, Bazarbachi A, Lepelletier Y, Canioni D et al. Persistent inhibition of telomerase reprograms adult T-cell leukemia to p53-dependent senescence. Blood 2006; 108: 1021-1029.

16 Kuwazuru Y, Hanada S, Furukawa T, Yoshimura A, Sumizawa T, Utsunomiya A et al. Expression of P-glycoprotein in adult T-cell leukemia cells. Blood 1990; 76: 2065-2071.

17 Ohno N, Tani A, Uozumi K, Hanada S, Furukawa T, Akiba S et al. Expression of functional lung resistance-related protein predicts poor outcome in adult T-cell leukemia. Blood 2001; 98: 1160-1165.

18 Ishida T, Jo T, Takemoto S, Suzushima H, Uozumi K, Yamamoto $\mathrm{K}$ et al. Dose-intensified chemotherapy alone or in combination with mogamulizumab in newly diagnosed aggressive adult T-cell leukaemia-lymphoma: a randomized phase II study. Br J Haematol 2015; 169: 672-682.

19 Bazarbachi A, Suarez F, Fields P, Hermine O. How I treat adult T-cell leukemia/ lymphoma. Blood 2011; 118: 1736-1745.

20 Bazarbachi A, Plumelle Y, Ramos JC, Tortevoye P, Otrock Z, Taylor G et al. Meta-analysis on the use of zidovudine and interferon-alfa in adult T-cell leukemia/lymphoma showing improved survival in the leukemic subtypes. J Clin Oncol 2010; 28: 4177-4183.

21 Gill P, Harrington W, Kaplan M, Ribeiro R, Bennett J, Liebman $\mathrm{H}$ et al. Treatment of adult T-cell leukemia-lymphoma with a combination of interferon alfa and zidovudine. N Engl J Med 1995; 332: 1744-1748.

22 Matutes E, Taylor GP, Cavenagh J, Pagliuca A, Bareford D, Domingo A et al. Interferon $\mathrm{a}$ and zidovudine therapy in adult T-cell leukaemia lymphoma: response and outcome in 15 patients. $\mathrm{Br} J$ Haematol 2001; 113: 779-784.

23 Hermine O, Bouscary D, Gessain A, Turlure P, Leblond V, Franck N et al. Brief report: treatment of adult T-cell leukemia-lymphoma with zidovudine and interferon alfa. N Engl J Med 1995; 332: 1749-1751.

24 Hodson A, Crichton S, Montoto S, Mir N, Matutes E, Cwynarski K et al. Use of zidovudine and interferon alfa with chemotherapy improves survival in both acute and lymphoma subtypes of adult T-cell leukemia/lymphoma. J Clin Oncol 2011; 29: 4696-4701.

25 Kchour G, Tarhini M, Kooshyar M-M, El Hajj H, Wattel E, Mahmoudi M et al. Phase 2 study of the efficacy and safety of the combination of arsenic trioxide, interferon alpha, and zidovudine in newly diagnosed chronic adult T-cell leukemia/ lymphoma (ATL). Blood 2009; 113: 6528-6532.

26 Hermine $\mathrm{O}$, Dombret $\mathrm{H}$, Poupon J, Arnulf B, Lefrère F, Rousselot $\mathrm{P}$ et al. Phase II trial of arsenic trioxide and alpha interferon in patients with relapsed/refractory adult T-cell leukemia/lymphoma. Hematol J 2004; 5: 130-134.

27 Ogura M, Imaizumi Y, Uike N, Asou N, Utsunomiya A, Uchida T et al. Lenalidomide in relapsed adult T-cell leukaemia-lymphoma or peripheral T-cell lymphoma (ATLL-001): a phase 1, multicentre, dose-escalation study. Lancet Haematol 2016; 3: $107-118$.

28 Nasr R, El-Sabban ME, Karam J-A, Dbaibo G, Kfoury Y, Arnulf B et al. Efficacy and mechanism of action of the proteasome inhibitor PS-341 in T-cell lymphomas and HTLV-I associated adult T-cell leukemia/lymphoma. Oncogene 2005; 24: 419-430.

29 Ishitsuka K, Utsunomiya A, Katsuya H, Takeuchi S, Takatsuka Y, Hidaka M et al. A phase II study of bortezomib in patients with relapsed or refractory aggressive adult T-cell leukemia/lymphoma. Cancer Sci 2015; 106: 1219-1223.

30 Yu P, Petrus M, Ju W, Zhang M, Conlon K, Nakagawa M et al. Augmented efficacy with the combination of blockade of the Notch-1 pathway, bortezomib and romidepsin in a murine MT-1 adult T-cell leukemia model. Leukemia 2015; 29: 556-566.

31 Ishida T, Joh T, Uike N, Yamamoto K, Utsunomiya A, Yoshida S et al. Defucosylated anti-CCR4 monoclonal antibody (KW-0761) for relapsed adult T-cell leukemia-lymphoma: A multicenter phase II study. J Clin Oncol 2012; 30: 837-842.

32 Berkowitz JL, Janik JE, Stewart DM, Jaffe ES, Stetler-Stevenson M, Shih JH et al. Safety, efficacy, and pharmacokinetics/pharmacodynamics of daclizumab (anti-CD25) in patients with adult T-cell leukemia/lymphoma. Clin Immunol 2014; 155: $176-187$.

33 Ceesay MM, Matutes E, Taylor GP, Fields P, Cavenagh J, Simpson S et al. Phase II study on combination therapy with CHOP-Zenapax for HTLV-I associated adult T-cell leukaemia/lymphoma (ATLL). Leuk Res 2012; 36: 857-861.

34 Mone A, Puhalla S, Whitman S, Baiocchi RA, Cruz J, Vukosavljevic T et al. Durable hematologic complete response and suppression of HTLV-1 viral load following alemtuzumab in zidovudine/IFN-a-refractory adult T-cell leukemia. Blood 2005; 106: 3380-3382.

35 Chen J, Pise-Masison CA, Shih JH, Morris JC, Janik JE, Conlon KC et al. Markedly additive antitumor activity with the combination of a selective survivin suppressant YM155 and alemtuzumab in adult T-cell leukemia. Blood 2013; 121: 2029-2037.

36 Kchour G, Rezaee R, Farid R, Ghantous A, Rafatpanah H, Tarhini M et al. The combination of arsenic, interferon-alpha, and zidovudine restores an 'immunocompetent-like' cytokine expression profile in patients with adult T-cell leukemia lymphoma. Retrovirology 2013; 10: 91

37 El Hajj H, El-Sabban M, Hasegawa H, Zaatari G, Ablain J, Saab ST et al. Therapy-induced selective loss of leukemia-initiating activity in murine adult $\mathrm{T}$ cell leukemia. J Exp Med 2010; 207: 2785-2792.

38 Kawada H, Yoshimitsu M, Nakamura D, Arai A, Hayashida M, Kamada $Y$ et al. A Retrospective Analysis of treatment outcomes in adult $\mathrm{T}$ cell leukemia/ lymphoma patients with aggressive disease treated with or without allogeneic stem cell transplantation: a single-center experience. Biol Blood Marrow Transplant 2015; 21: 696-700.

39 Tsukasaki K, Maeda T, Arimura K, Taguchi J, Fukushima T, Miyazaki $\mathrm{Y}$ et al. Poor outcome of autologous stem cell transplantation for adult T cell leukemia/ lymphoma: a case report and review of the literature. Bone Marrow Transplant 1999; 23: 87-89.

40 Phillips A, Willim R, Savage D, Horwitz S, Isola L, Zain J et al. A multi-institutional experience of autologous stem cell transplantation in North American patients with human T-cell lymphotropic virus type-1 adult T-cell leukemia/lymphoma suggests ineffective salvage of relapsed patients. Leuk Lymphoma 2009; 50: 1039-1042.

41 Bazarbachi A, Cwynarski K, Boumendil A, Finel H, Fields P, Raj K et al. Outcome of patients with HTLV-1-associated adult T-cell leukemia/lymphoma after SCT: a retrospective study by the EBMT LWP. Bone Marrow Transplant 2014; 49: 1266-1268.

42 Ohno E, Ono K, Kikuchi H, Saburi Y, Utsunomiya A, Nasu M. Prolonged remission of adult T-cell leukemia/lymphoma treated with interferon-gamma following autologous peripheral blood stem cell transplantation. Leuk Lymphoma 2005; 46: 1843-1845.

43 Fujiwara H, Arima N, Akasaki Y, Ohtsubo H, Ozaki A, Kukita T et al. Interferon-alpha therapy following autologous peripheral blood stem cell transplantation for adult T cell leukemia/lymphoma. Acta Haematol 2002; 107: 213-219.

44 Hishizawa M, Kanda J, Utsunomiya A, Taniguchi S, Eto T, Moriuchi $\mathrm{Y}$ et al. Transplantation of allogeneic hematopoietic stem cells for adult T-cell leukemia: a nationwide retrospective study. Blood 2010; 116: 1369-1376.

45 Tholouli E, Liu Yin JA. Successful treatment of HTLV-1-associated acute adult T-cell leukemia lymphoma by allogeneic bone marrow transplantation: a 12 year follow-up. Leuk Lymphoma 2006; 47: 1691-1692.

46 Choi I, Tanosaki R, Uike N, Utsunomiya A, Tomonaga M, Harada M et al. Long-term outcomes after hematopoietic SCT for adult T-cell leukemia/lymphoma: results of prospective trials. Bone Marrow Transplant 2011; 46: 116-118.

47 Ishida T, Hishizawa M, Kato K, Tanosaki R, Fukuda T, Taniguchi S et al. Allogeneic hematopoietic stem cell transplantation for adult T-cell leukemia-lymphoma with special emphasis on preconditioning regimen: a nationwide retrospective study. Blood 2012; 120: 1734-1741.

48 Morishima $\mathrm{Y}$, Kodera $\mathrm{Y}$, Hirabayashi N, Tanimoto M, Matsuyama T, Horibe $\mathrm{K}$ et al. Low incidence of acute GVHD in patients transplanted with marrow from HLA-A,B, DR-compatible unrelated donors among Japanese. Bone Marrow Transplant 1995; 15: 235-239.

49 Ishida T, Hishizawa M, Kato K, Tanosaki R, Fukuda T, Takatsuka Y et al. Impact of graft-versus-host disease on allogeneic hematopoietic cell transplantation for adult $\mathrm{T}$ cell leukemia-lymphoma focusing on preconditioning regimens: nationwide retrospective study. Biol Blood Marrow Transplant 2013; 19: 1731-1739. 
50 Fuji S, Fujiwara H, Nakano N, Wake A, Inoue Y, Fukuda T et al. Early application of related SCT might improve clinical outcome in adult T-cell leukemia/lymphoma. Bone Marrow Transplant 2016; 51: 205-211.

51 Shigematsu A, Kobayashi N, Yasui H, Shindo M, Kakinoki Y, Koda K et al. High level of serum soluble interleukin-2 receptor at transplantation predicts poor outcome of allogeneic stem cell transplantation for adult t cell leukemia. Biol Blood Marrow Transplant 2014; 20: 801-805.

52 Okamura J, Utsunomiya A, Tanosaki R, Uike N, Sonoda S, Kannagi M et al. Allogeneic stem-cell transplantation with reduced conditioning intensity as a novel immunotherapy and antiviral therapy for adult T-cell leukemia/lymphoma. Blood 2005; 105: 4143-4145.

53 Tanosaki R, Uike N, Utsunomiya A, Saburi Y, Masuda M, Tomonaga M et al. Allogeneic hematopoietic stem cell transplantation using reduced-intensity conditioning for adult $\mathrm{T}$ cell leukemia/lymphoma: impact of antithymocyte globulin on clinical outcome. Biol Blood Marrow Transplant 2008; 14: 702-708.

54 Momita S, Ikeda S, Amagasaki T, Soda H, Yamada Y, Kamihira S et al. Survey of anti-human T-cell leukemia virus type I antibody in family members of patients with adult T-cell leukemia. Japanese J Cancer Res 1990; 81: 884-889.

55 Tamaki H, Matsuoka M. Donor-derived T-cell leukemia after bone marrow transplantation. N Engl J Med 2006; 354: 1758-1759.

56 Nakamizo A, Akagi Y, Amano T, Suzuki SO, Otsuka R, Abe Y et al. Donor-derived adult T-cell leukaemia. Lancet 2011; 377: 1124

57 Anthony Nolan and NHS Blood and Transplant. Together for Better-Anthony Nolan and NHS Stem Cell Registry Annual Review 2014. http://www.nhsbt.nhs.uk/ download/news_110314.pdf.

58 Izutsu K, Kanda Y, Ohno H, Sao H, Ogawa H, Miyazaki $Y$ et al. Unrelated bone marrow transplantation for non-Hodgkin lymphoma: a study from the Japan Marrow Donor Program. Blood 2004; 103: 1955-1960.

59 Nakase K, Hara M, Kozuka T, Tanimoto K, Nawa Y. Bone marrow transplantation from unrelated donors for patients with adult T-cell leukaemia/lymphoma. Bone Marrow Transplant 2006; 37: 41-44.

60 Kato K, Kanda Y, Eto T, Muta T, Gondo H, Taniguchi $S$ et al. Allogeneic bone marrow transplantation from unrelated human T-cell leukemia virus-I-negative donors for adult T-Cell leukemia/lymphoma: retrospective analysis of data from the japan marrow donor program. Biol Blood Marrow Transplant 2007; 13: 90-99.

61 Obama K, Utsunomiya A, Takatsuka Y, Takemoto Y. Reduced-intensity non-T-cell depleted HLA-haploidentical stem cell transplantation for older patients based on the concept of feto-maternal tolerance. Bone Marrow Transplant 2004; 34: 897-899.

62 Ringdén O, Labopin M, Ciceri F, Velardi A, Bacigalupo A, Arcese W et al. Is there a stronger graft-versus-leukemia effect using HLA-haploidentical donors than with HLA-identical siblings? Leukemia 2015; 30: 447-455.

63 Kasamon YL, Bolanos-Meade J, Prince GT, Tsai H-L, McCurdy SR, Kanakry JA et al. Outcomes of nonmyeloablative HLA-haploidentical blood or marrow transplantation with high-dose post-transplantation cyclophosphamide in older adults. J Clin Oncol 2015; 33: 3152-3161.

64 Bashey A, Zhang X, Sizemore CA, Manion K, Brown S, Holland HK et al. T-cell-replete HLA-haploidentical hematopoietic transplantation for hematologic malignancies using post-transplantation cyclophosphamide results in outcomes equivalent to those of contemporaneous HLA-matched related and unrelated donor transplantation. J Clin Oncol 2013; 31: 1310-1316.

65 Narimatsu H, Murata M, Sugimoto K, Terakura S, Kinoshita T, Naoe T. Successful umbilical cord blood transplantation using a reduced-intensity preparative regimen without total body irradiation and tacrolimus plus methotrexate for prophylaxis of graft-versus-host disease in a patient with adult T-cell leukemia/ lymphoma. Leuk Lymphoma 2007; 48: 841-843.

66 Takizawa J, Aoki S, Kurasaki T, Higashimura M, Honma K, Kitajima T et al. Successful treatment of adult T-cell leukemia with unrelated cord blood transplantation. Am J Hematol 2007; 82: 1113-1115.

67 Fukushima T, Itonaga H, Moriuchi $\mathrm{Y}$, Yoshida S, Taguchi J, Imaizumi $\mathrm{Y}$ et al. Feasibility of cord blood transplantation in chemosensitive adult T-cell leukemia/lymphoma: A retrospective analysis of the nagasaki transplantation network. Int J Hematol 2013; 97: 485-490.

68 Rodrigues CA, Rocha V, Dreger P, Brunstein C, Sengeloev H, Finke J et al. Alternative donor hematopoietic stem cell transplantation for mature lymphoid malignancies after reduced-intensity conditioning regimen: Similar outcomes with umbilical cord blood and unrelated donor peripheral blood. Haematologica 2014; 99: 370-377.

69 Matsushita K, Arima N. Involvement of granulocyte colony-stimulating factor in proliferation of adult T-cell leukemia cells. Leuk Lymphoma 1998; 31: 295-304.

70 Matsushita K, Arima N, Ohtsubo H, Fujiwara H, Hidaka S, Kukita T et al. Granulocyte-colony stimulating factor-induced proliferation of primary adult T-cell leukaemia cells. Br J Haematol 1997; 96: 715-723.
71 Itonaga H, Taguchi J, Fukushima T, Tsushima H, Sato S, Ando K et al. Distinct clinical features of infectious complications in adult T Cell leukemia/lymphoma patients after allogeneic hematopoietic stem cell transplantation: a retrospective analysis in the nagasaki transplant group. Biol Blood Marrow Transplant 2013; 19: 607-615.

72 Shiratori S, Yasumoto A, Tanaka J, Shigematsu A, Yamamoto S, Nishio M et al. A retrospective analysis of allogeneic hematopoietic stem cell transplantation for adult $\mathrm{T}$ cell leukemia/lymphoma (ATL): clinical impact of graftversus-leukemia/lymphoma effect. Biol Blood Marrow Transplant 2008; 14: 817-823.

73 Yonekura K, Utsunomiya A, Takatsuka Y, Takeuchi S, Tashiro Y, Kanzaki T et al. Graft-versus-adult T-cell leukemia/lymphoma effect following allogeneic hematopoietic stem cell transplantation. Bone Marrow Transplant 2008; 41: 1029-1035.

74 Itonaga $\mathrm{H}$, Tsushima $\mathrm{H}$, Taguchi J, Fukushima $\mathrm{T}$, Taniguchi $\mathrm{H}$, Sato $\mathrm{S}$ et al. Treatment of relapsed adult T-cell leukemia/lymphoma after allogeneic hematopoietic stem cell transplantation: the Nagasaki Transplant Group experience. Blood 2013; 121: 219-225.

75 Kamimura T, Miyamoto T, Kawano N, Numata A, Ito Y, Chong Y et al. Successful treatment by donor lymphocyte infusion of adult T-cell leukemia/lymphoma relapse following allogeneic hematopoietic stem cell transplantation. Int J Hematol 2012; 95: 725-730.

76 Harashima N, Kurihara K, Utsunomiya A, Tanosaki R, Hanabuchi S, Masuda M et al. Graft-versus-Tax response in adult T-cell leukemia patients after hematopoietic stem cell transplantation. Cancer Res 2004; 64: 391-399.

77 Narita T, Ishida T, Masaki A, Suzuki S, Ito A, Mori F et al. HTLV-1 bZIP factor-specific CD4 $T$ cell responses in adult $T$ cell leukemia/lymphoma patients after allogeneic hematopoietic stem cell transplantation. J Immunol 2014; 192: 940-947.

78 Masaki A, Ishida T, Suzuki S, Ito A, Mori F, Sato F et al. Autologous Tax-specific CTL therapy in a primary adult T cell leukemia/lymphoma cell-bearing NOD/Shi-scid, IL-2Rynull mouse model. J Immunol 2013; 191: 135-144.

79 Tanaka Y, Yamazaki R, Terasako-Saito K, Nakasone H, Akahoshi Y, Nakano H et al. Universal cytotoxic activity of a HTLV-1 Tax-specific T cell clone from an HLA$A^{*} 24: 02+$ patient with adult T-cell leukemia against a variety of HTLV-I-infected T-cells. Immunol Lett 2014; 158: 120-125.

80 Harashima N, Tanosaki R, Shimizu Y, Kurihara K, Masuda T, Okamura J et al. Identification of two New HLA-A*1101-restricted tax epitopes recognized by cytotoxic $T$ lymphocytes in an adult T-cell leukemia patient after hematopoietic stem cell transplantation. J Virol 2005; 79: 10088-10092.

81 Sugata K, Yasunaga J, Mitobe Y, Miura M, Miyazato P, Kohara M et al. Protective effect of cytotoxic T lymphocytes targeting HTLV-1 bZIP factor. Blood 2015; 126: 1095-1105.

82 Tamai Y, Hasegawa A, Takamori A, Sasada A, Tanosaki R, Choi I et al. Potential contribution of a novel Tax epitope-specific CD4+ T cells to graft-versus-Tax effect in adult $\mathrm{T}$ cell leukemia patients after allogeneic hematopoietic stem cell transplantation. J Immunol 2013; 190: 4382-4392.

83 Tanaka $\mathrm{Y}$, Nakasone $\mathrm{H}$, Yamazaki $\mathrm{R}$, Wada $\mathrm{H}$, Ishihara $\mathrm{Y}$, Kawamura $\mathrm{K}$ et al. Long-term persistence of limited HTLV-1 Tax-specific cytotoxic T cell clones in a patient with adult T-cell leukemia/lymphoma after allogeneic stem cell transplantation. J Clin Immunol 2012; 32: 1340-1352.

84 Miyazaki Y, Fujiwara H, Asai H, Ochi F, Ochi T, Azuma T et al. Development of a novel redirected T-cell-based adoptive immunotherapy targeting human telomerase reverse transcriptase for adult T-cell leukemia. Blood 2013; 121: 4894-4901.

85 Ito Y, Miyamoto T, Chong Y, Aoki T, Kato K, Akashi K et al. Successful treatment with anti-CC chemokine receptor $4 \mathrm{MoAb}$ of relapsed adult T-cell leukemia/ lymphoma after umbilical cord blood transplantation. Bone Marrow Transplant 2013; 48: 998-999.

86 Inoue Y, Fuji S, Tanosaki R, Fukuda T. Pretransplant mogamulizumab against ATLL might increase the risk of acute GvHD and non-relapse mortality. Bone Marrow Transplant 2015; 51: 725-727.

87 Haji S, Kiyasu J, Choi I, Suehiro Y, Toyoda K, Tsuda M et al. Administration of an anti-CC chemokine receptor 4 monoclonal antibody, mogamulizumab, before allogeneic bone marrow transplantation for adult T-cell leukemia/lymphoma. Bone Marrow Transplant 2016; 51: 432-434.

88 Ljungman P, Lawler M, Asjö B, Bogdanovic G, Karlsson K, Malm C et al. Infection of donor lymphocytes with human T lymphotrophic virus type 1 (HTLV-I) following allogeneic bone marrow transplantation for HTLV-I positive adult T-cell leukaemia. Br J Haematol 1994; 88: 403-405.

89 Kawamata T, Ohno N, Sato K, Kobayashi M, Jo N, Yuji K et al. A case of posttransplant adult T-cell leukemia/lymphoma presenting myelopathy similar to but distinct from human T-cell leukemia virus type I (HTLV- I)-associated myelopathy. Springerplus 2014; 3: 581 
90 Ramanan P, Deziel PJ, Norby SM, Yao JD, Garza I, Razonable RR. Case report donor-transmitted HTLV-1-associated myelopathy in a kidney transplant recipient-case report and literature review. Am J Transplant 2014; 14: 2417-2421.

91 Ogata M, Ogata Y, Imamura T, Ohtsuka E, Kikuchi H, Utsunomiya A et al. Successful bone marrow transplantation from an unrelated donor in a patient with adult T cell leukemia. Bone Marrow Transplant 2002; 30: 699-701.

92 Tajima K, Amakawa R, Uehira K, Matsumoto N, Shimizu T, Miyazaki Y et al. Adult T-cell leukemia successfully treated with allogeneic bone marrow transplantation. Int J Hematol 2000; 71: 290-293.

93 Abe Y, Yashiki S, Choi I, Hara K, Matsushima T, Nishimura J et al. Eradication of virus-infected T-cells in a case of adult T-cell leukemia/lymphoma by nonmyeloablative peripheral blood stem cell transplantation with conditioning consisting of low-dose total body irradiation and pentostatin. Int J Hematol 2002; 76: 91-93.

94 Okamura J, Uike N, Utsunomiya A, Tanosaki R. Allogeneic stem cell transplantation for adult T-cell leukemia/lymphoma. Int J Hematol 2007; 86: 118-125.

95 Gillet Na, Malani N, Melamed A, Gormley N, Carter R, Bentley D et al. The host genomic environment of the provirus determines the abundance of HTLV-1-infected T-cell clones. Blood 2011; 117: 3113-3122.

96 Cook LB, Melamed A, Niederer H, Valganon M, Laydon D, Foroni L et al. The role of HTLV-1 clonality, proviral structure, and genomic integration site in adult T-cell leukemia/lymphoma. Blood 2014; 123: 3925-3931. 